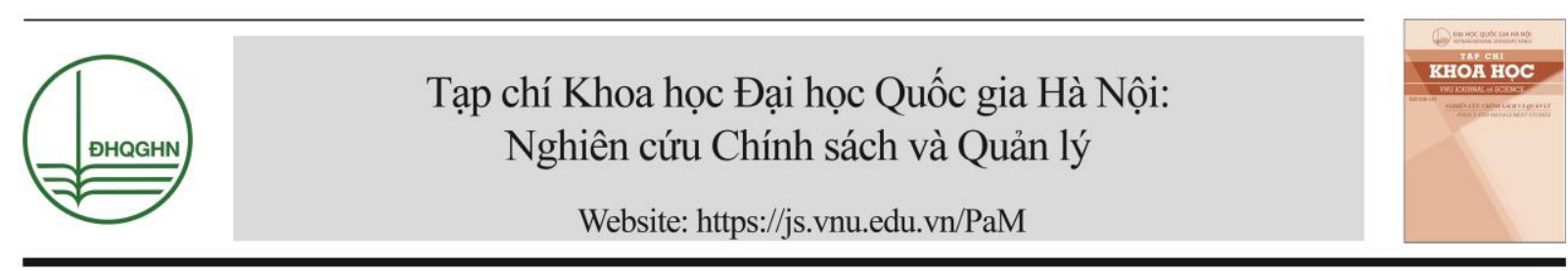

\title{
Sự hỗ trợ của mạng lưới khám chữa bệnh đối với người trong độ tuổi lao động ở nông thôn
}

\author{
Phạm Gia Cường* \\ Vu Các vấn đề Xã hội, Ban Tuyên giáo Trung uoong, $2 B$ Hoàng Văn Thụ, Ba Đình, Hà Nội, Việt Nam \\ Nhận ngày 05 tháng 08 năm 2017 \\ Chỉnh sửa ngày 15 tháng 11 năm 2017; Chấp nhận đăng ngày 22 tháng 01 năm 2018
}

\begin{abstract}
Tóm tắt: Bài viết tập trung phân tích sự hỗ trợ của mạng lưới xã hội và tiếp cận dịch vụ y tế thông qua mạng lưới xã hội của người trong độ tuổi lao động ở nông thôn theo cơ cấu kinh tế xã hội khác nhau, từ đó xác định vai trò của thành viên mạng lưới xã hội trong việc hỗ trợ khám chữa bệnh cho đối tượng khảo sát.
\end{abstract}

Tù khóa: Khám chữa bệnh, Hỗ trợ xã hội, Mạng lưới xã hội, Người trong độ tuổi lao động.

\section{1. Đề dẫn}

Hỗ trợ xã hội (HTXH) được định nghĩa theo nhiều cách khác nhau. Tuy nhiên, hầu hết các định nghĩa đều nhấn mạnh đó là một loại "tài nguyên" mà một người sẽ sẵn có hoặc nhận thức là có sẵn từ gia đình, bạn bè và những người quen biết [1]. Các nhà nghiên cứu thường sử dụng phương pháp phân tích mạng lưới xã hội (MLXH) để hiểu về HTXH. Trong các tài liệu, MLXH và HTXH là những khái niệm thường được sử dụng thay thế cho nhau. Tuy nhiên, nghiên cứu MLXH có xu hướng tập trung vào những mối quan hệ xã hội. Nghiên cứu $\mathrm{HTXH}$ thường đi sâu nhiều hơn vào sự đóng góp của các thành viên trong MLXH. HTXH diễn ra thông qua các mối quan hệ trong

\footnotetext{
* ĐT.: 84-983484398.

Email: phamgiacuong0201@gmail.com https://doi.org/10.25073/2588-1116/vnupam.4074
}

mạng lưới xã hội. Do đó, không thể nghiên cứu về HTXH mà không xem xét đến MLXH, nơi việc cho và nhận hỗ trợ được thực hiện thông qua các mối quan hệ xã hội có cơ cấu trong MLXH. Ngoài ra, nghiên cứu về MLXH và HTXH đều dựa trên cơ sở hành vi cá nhân chịu sự chi phối của các cá nhân khác. Do đó, không thể nghiên cứu về HTXH mà không xem xét đến MLXH.

Năm 1976, S. Cobb định nghĩa, HTXH là "thông tin dẫn đối tượng đến niềm tin rằng mình được chăm sóc và yêu thương, được coi trọng, đánh giá cao và thuộc về một mạng lưới giao tiếp và có ràng buộc lẫn nhau" [2]. Định nghĩa của $\mathrm{S}$. Cobb tập trung chủ yếu vào những hỗ trợ phi vật chất. Năm 1981, C.A. Heaney và B.A. Israel đã đưa ra 4 loại $\mathrm{HTXH}$ chính: tình cảm, công cụ, thông tin và đánh giá, như hình 1 [3]. 


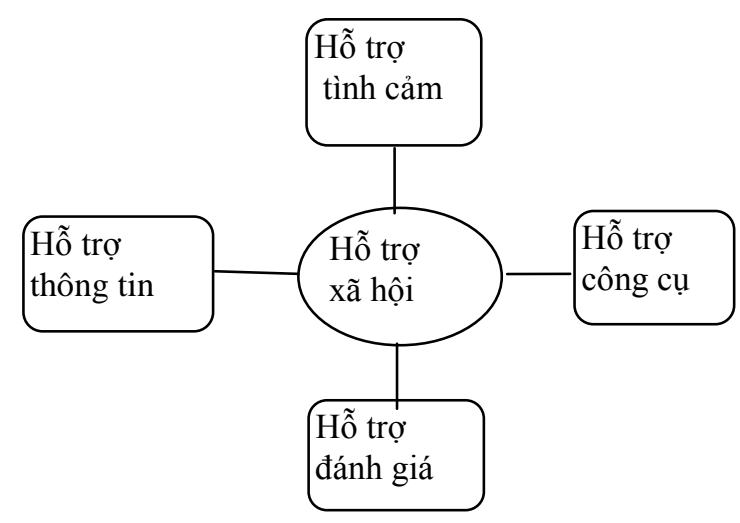

Hình 1. Bốn loại hỗ trợ xã hội chính

Theo các tác giả, trong bốn loại HTXH, hỗ trợ công cụ là những HTXH hữu hình. Các loại kia đều mang tính trừu tượng. Hỗ trọ công cu mang đến cho người thụ hưởng những thứ hoặc những dịch vụ có lợi trực tiếp (ví dụ: công lao động, tiền, hiện vật,...). Hố trợ tình cảm bao gồm những giúp đỡ về cảm xúc, ví dụ: tình yêu thương, sự đồng cảm, sự quan tâm và tin tưởng. Hỗ trọ thông tin là sự giúp đỡ bằng cách cung cấp thông tin và lời khuyên hay hướng dẫn/gợi ý để giúp người thụ hưởng giải quyết vấn đề của riêng mình. Hỗ trợ đánh giá là việc giúp người đó bằng cách đưa ra các thông tin có ích nhờ đó họ tự đánh giá bản thân. HTXH theo loại này có thể là các phản hồi mang tính xây dựng hoặc những lời xác nhận.

Trong nghiên cứu này, chúng tôi tập trung xem xét các loại HTXH về tình cảm, thông tin, công cụ và tiếp cận dịch vụ y tế đối với người trong độ tuổi lao động (TĐTLĐ) ở nông thôn. Trong đó, chúng tôi tách loại hỗ trợ về thông tin thành hai nhóm nhỏ: hỗ trợ không chính thức về thông tin (gọi tắt là thông tin) và hỗ trợ chính thức theo cách tư vấn của nhà chuyên môn (gọi tắt là tư vấn).

Nghiên cứu được tiến hành năm 2016 tại 03 xã (mỗi xã chọn 3 thôn) có cơ cấu kinh tế khác nhau của huyện Thường Tín, thành phố Hà Nội. Các xã và thôn được chọn theo phương pháp ngẫu nhiên phân cụm. Khảo sát được tiến hành với 300 người trong độ tuổi lao động (TĐTLĐ) có tiền sử bị ốm đau, bệnh tật và trải nghiệm khám chữa bệnh tối thiểu 12 tháng trước điều tra ở 09 thôn thuộc 03 xã được xác định theo phương pháp chọn mẫu ngẫu nhiên thuận tiện từ danh sách do các cơ sở y tế và nhân viên y tế thôn cung cấp. Thông tin chủ yếu được khảo sát bao gồm: những đặc điểm nhân khẩu học - xã hội (giới tính, độ tuổi, trình độ học vấn, tình trạng việc làm, hôn nhân, mức sống, tham gia bảo hiểm y tế) và đặc điểm ốm đau, bệnh tật (loại, mức độ, khoảng thời gian và nhận biết dấu hiệu ốm đau, bệnh tật); đặc điểm của MLXH trong khám chữa bệnh, nội dung và mức độ hỗ trợ của MLXH và tiếp cận dịch vụ y tế của đối tượng được khảo sát thông qua sự hỗ trợ của MLXH.

Bài báo giới thiệu một số phát hiện chính của nghiên cứu, trong phạm vi cho phép của bài viết, chúng tôi chỉ tập trung phân tích nội dung và mức độ $\mathrm{HTXH}$ trong khám chữa bệnh của các thành viên MLXH đối với người TĐTLĐ và việc tiếp cận, phản hồi về dịch vụ y tế của đối tượng được khảo sát.

\section{Hỗ trợ của mạng lưới xã hội đối với người trong độ tuổi lao động}

\subsection{Về nội dung hỗ trọ̆ của mạng lưới xã hội}

Nhìn chung, theo ý kiến của người được khảo sát, những hỗ trợ mà họ nhận được không đồng đều cả về loại và nguồn hỗ trợ. Loại hỗ trợ thường nhận được là tình cảm từ thành viên gia đình $(94,0 \%)$ và thông tin từ người có hoàn cảnh ốm đau, bệnh tật $(90,0 \%)$. Loại hỗ trợ bằng hiện vật có tỷ lệ thấp từ tất cả các nguồn hỗ trợ trong MLXH của họ (từ mức cao nhất chỉ là $15,7 \%$, đến mức thấp nhất là $0.7 \%$ ). Loại hỗ trợ về tiền bạc chủ yếu xuất phát từ thành viên gia đình (54,7\%). Đối tượng thường không nhận được sự hỗ trợ về tài chính từ các mối quan hệ ngoài gia đình, quan hệ công việc và với nhân viên y tế. So với loại hỗ trợ về hiện vật, loại hỗ trợ tài chính nhiều hơn về tỷ lệ nhưng không trải rộng về các nguồn hỗ trợ như hỗ trợ về hiện vật. Thực tế cho thấy, khi một người ốm đau bình thường thì người hỗ trợ chủ yếu là thành viên gia đình và những người 
ngoài gia đình chỉ đến hỏi thăm khi người đó ốm nặng, bị bệnh. Kết quả khảo sát cũng phù hợp với thực tế là việc thăm hỏi thường xảy ra trong những quan hệ ràng buộc qua lại như quan hệ gia đình, họ hàng, láng giềng và quan hệ công việc.

Bảng 1. Sự hỗ trợ của thành viên mạng lưới xã hội đối với người trong độ tuổi lao động

\begin{tabular}{|c|c|c|c|c|c|c|c|}
\hline \multirow[b]{2}{*}{ STT } & \multirow[b]{2}{*}{ Nguồn hỗ trợ } & \multicolumn{6}{|c|}{ Loại hỗ trợ } \\
\hline & & $\begin{array}{l}\text { Tiền } \\
(\%)\end{array}$ & $\begin{array}{l}\text { Hiện } \\
\text { vật } \\
(\%)\end{array}$ & $\begin{array}{l}\text { Tình } \\
\text { cảm } \\
(\%)\end{array}$ & $\begin{array}{l}\text { Thông } \\
\text { tin } \\
(\%)\end{array}$ & $\begin{array}{l}\text { Tư } \\
\text { vấn } \\
(\%)\end{array}$ & $\begin{array}{l}\text { Chưa } \\
\text { hỗ trọ } \\
(\%)\end{array}$ \\
\hline 1 & Thành viên gia đình & 54,7 & 15,7 & 94,0 & 20,3 & 8,7 & 0,0 \\
\hline 2 & Họ hàng & 5,7 & 13,0 & 63,7 & 55,7 & 3,0 & 0,0 \\
\hline 3 & Hàng xóm & 0,0 & 8,0 & 52,0 & 58,3 & 2,7 & 6,0 \\
\hline 4 & Bạn bè & 0,0 & 2,0 & 36,7 & 79,3 & 6,7 & 2,0 \\
\hline 5 & Đồng nghiệp & 0,7 & 2,3 & 38,0 & 76,7 & 11,0 & 2,7 \\
\hline 6 & $\begin{array}{l}\text { Chính quyền địa phương, } \\
\text { cơ quan, tổ chức }\end{array}$ & 0,0 & 7,0 & 14,3 & 36,0 & 4,7 & 47,0 \\
\hline 7 & Nhân viên y tế & 0,3 & 1,0 & 15,0 & 56,0 & 71,7 & 0,0 \\
\hline 8 & $\begin{array}{l}\text { Người cùng hoàn cảnh ốm } \\
\text { đau, bệnh tật }\end{array}$ & 0,0 & 0,7 & 34,0 & 90,0 & 5,3 & 2,0 \\
\hline
\end{tabular}

Thông qua MLXH, người TĐTLĐ nhận được sự hỗ trợ chủ yếu về thông tin từ các mối quan hệ ngoài gia đình. Đặc biệt sự hỗ trợ về thông tin của người có cùng hoàn cảnh ốm đau, bệnh tật. Người có cùng hoàn cảnh ốm đau, bệnh tật có nhiều thông tin về y tế và sức khỏe là do họ có kinh nghiệm sử dụng dịch vụ y tế, tìm hiểu về ốm đau, bệnh tật,... Điều đó phù hợp với khẳng định của $\mathrm{M}$. S. Granovetter là các mối quan hệ yếu quan trọng hơn cho việc truyền thông tin mới trong MLXH. Quan hệ giữa đối tượng và người có cùng hoàn cảnh ốm đau, bệnh tật là một mối quan hệ yếu do mới hình thành và có tính chất tình huống. Kiểu quan hệ này cho phép phạm vi thông tin rộng hơn so với các mối quan hệ mạnh có xu hướng hiểu biết lẫn nhau và duy trì mức độ thông tin tương tự. Theo lý thuyết của Granovetter những thông tin quan trọng và hữu ích nhất thu được từ các cá nhân khi họ đương đầu với vấn đề mới trong mối quan hệ "thỉnh thoảng hoặc hiếm có" [4].

Chính quyền địa phương, cơ quan, tổ chức có vai trò tổ chức, cung cấp và quản lý dịch vụ $\mathrm{y}$ tế, cung cấp thông tin về chính sách cho người TĐTLĐ nhưng có tỷ lệ thấp $(36,0 \%)$. Đặc biệt, 47\% người TĐTLĐ cho rằng họ chưa nhận được sự hỗ trợ của chính quyền địa phương, cơ quan, tổ chức.

Nhân viên y tế có vai trò quan trọng đối với người bệnh thông qua uy tín và khả năng khám chữa bệnh, nhưng người TĐTLĐ cho rằng sự hỗ trợ của nhân viên y tế về thông tin chỉ cao hơn sự hỗ trợ của họ hàng và thấp hơn sự hỗ trợ của hàng xóm, bạn bè, đồng nghiệp. Thế mạnh của nhân viên y tế là tư vấn cho người bệnh về cách điều trị, chăm sóc sức khỏe và sử dụng dịch vụ y tế đã được người TĐTLĐ khẳng định. Có một lý do dùng để giải thích tỷ lệ hỗ trợ về tình cảm của nhân viên y tế là tình trạng quá tải bệnh viện và công việc liên quan đến sự sống còn của người bệnh đã làm tăng cường độ lao động nhân viên y tế.

Kết quả khảo sát cũng cho thấy, mối tương quan có ý nghĩa thống kê giữa cơ cấu kinh tế với các loại hỗ trợ của thành viên gia đình về tiền, hiện vật, tình cảm, thông tin và tư vấn $(\mathrm{p}=0,000 ; 0,000 ; 0,001 ; 0,000 ; 0,000)$; giữa cơ cấu kinh tế với các loại hỗ trợ của họ hàng về tiền, hiện vật, tình cảm và tư vấn $(\mathrm{p}=0,000$; $0,000 ; 0,000 ; 0,011)$; giữa cơ cấu kinh tế với các loại hỗ trợ của hàng xóm về hiện vật, tình cảm và chưa hỗ trợ $(\mathrm{p}=0,000 ; 0,000 ; 0,024)$; giữa cơ cấu kinh tế với các loại hỗ trợ của bạn 
bè về tình cảm, thông tin và tư vấn $(\mathrm{p}=0,000$; $0,001 ; 0,004)$; giữa cơ cấu kinh tế với các loại hỗ trợ của đồng nghiệp về hiện vật, tình cảm, thông tin, tư vấn và chưa hỗ trợ $(\mathrm{p}=0,001$; $0,000 ; 0,026 ; 0,002)$; giữa cơ cấu kinh tế với các loại hỗ trợ của người cùng hoàn cảnh ốm đau, bệnh tật về về tình cảm và chưa hỗ trợ ( $\mathrm{p}=0,007 ; 0,028$ ); giữa cơ cấu kinh tế với sự hỗ trợ của nhân viên y tế về tình cảm, thông tin và tư vấn $(\mathrm{p}=0,003 ; 0,000 ; 0,004)$; giữa cơ cấu kinh tế với sự chưa hỗ trợ của chính quyền địa phương, cơ quan, tổ chức về hiện vật, thông tin và chưa hỗ trợ người TĐTLĐ $(\mathrm{p}=0,000 ; 0,000 ; 0,000)$.

Tuy nhiên, kết quả khảo sát cho thấy mối tương quan không có ý nghĩa thống kê giữa cơ cấu kinh tế với sự hỗ trợ của bạn bè, nhân viên y tế và người có cùng hoàn cảnh ốm đau, bệnh tật về hiện vật $(\mathrm{p}=0,130 ; 0,364 ; 0,134)$. Mối tương quan không có ý nghĩa thống kê giữa co cấu kinh tế với sự hỗ trợ của đồng nghiệp và nhân viên y tế về tiền $(\mathrm{p}=0,604 ; 0,367)$. Mối tương quan không có ý nghĩa thống kê giữa cơ cấu kinh tế với sự hỗ trợ của họ hàng, hàng xóm và người cùng hoàn cảnh ốm đau, bệnh tật về thông tin ( $\mathrm{p}=0,0893 ; 0,0367 ; 0,236)$. Mối tương quan không có ý nghĩa thống kê giữa cơ cấu kinh tế với sự hỗ trợ của hàng xóm, chính quyền, cơ quan, tổ chức và người cùng hoàn cảnh ốm đau, bệnh tật về tư vấn $(\mathrm{p}=0,087$; $0,387 ; 0,157)$.

\subsection{Về mức độ hỗ trợ của mạng luới xã hội}

Kết quả khảo sát ở bảng 2 cho thấy các thành viên gia đình hỗ trợ thường xuyên người TĐTLĐ. Các mối quan hệ ngoài gia đình tập trung ở mức độ hỗ trợ thỉnh thoảng. Có tỷ lệ đáng kể người TĐTLĐ hiếm khi nhận được sự hỗ trợ từ hàng xóm $(58,7 \%)$, chính quyền địa phương, cơ quan, tổ chức $(51,0 \%)$ và nhân viên $\mathrm{y}$ tế $(43,7 \%)$. Ngoài ra, 38,3\% người TĐTLĐ chưa nhận được sự hỗ trợ của chính quyền địa phương, cơ quan, tổ chức. Mức độ hỗ trợ trên bộc lộ sự khác biệt nhất định xét về sự ràng buộc trong MLXH của họ liên quan đến khám chữa bệnh so với kiểu MLXH thông thường của cá nhân. Trong đó, tính chất mạnh yếu của các mối quan hệ xét về mức độ hỗ trợ theo trật tự: thành viên gia đình, họ hàng, nhân viên y tế,....

Bảng 2. Mức độ hỗ trợ của MLXH đối với người trong độ tuổi lao động

\begin{tabular}{|c|c|c|c|c|c|c|c|}
\hline \multirow[b]{2}{*}{ STT } & \multirow[b]{2}{*}{ Người hỗ trợ } & \multicolumn{5}{|c|}{ Mức độ hỗ trợ } & \multirow[b]{2}{*}{ Tổng } \\
\hline & & $\begin{array}{l}\text { Rất } \\
\text { thường } \\
\text { xuyên }\end{array}$ & $\begin{array}{l}\text { Thường } \\
\text { xuyên }\end{array}$ & $\begin{array}{l}\text { Thỉnh } \\
\text { thoảng }\end{array}$ & $\begin{array}{l}\text { Hiếm } \\
\text { khi }\end{array}$ & $\begin{array}{l}\text { Chưa } \\
\text { nhận } \\
\text { được }\end{array}$ & \\
\hline 1 & $\begin{array}{l}\text { Thành viên gia } \\
\text { đình }\end{array}$ & 19,3 & 73,0 & 7,7 & 0,0 & 0,0 & 100,0 \\
\hline 2 & Họ hàng & 0,7 & 16,3 & 72,0 & 11,0 & 0,0 & 100,0 \\
\hline 3 & Hàng xóm & 0,0 & 2,0 & 37,0 & 58,7 & 2,3 & 100,0 \\
\hline 4 & Bạn bè & 0,0 & 6,0 & 68,3 & 24,7 & 1,0 & 100,0 \\
\hline 5 & Đồng nghiệp & 0,0 & 6,7 & 66,0 & 25,7 & 1,7 & 100,0 \\
\hline 6 & $\begin{array}{l}\text { Chính quyền địa } \\
\text { phương, cơ quan, tổ } \\
\text { chức }\end{array}$ & 0,0 & 0,7 & 10,0 & 51,0 & 38,3 & 100,0 \\
\hline 7 & Nhân viên y tế & 0,3 & 13,7 & 41,3 & 43,7 & 1,0 & 100,0 \\
\hline 8 & $\begin{array}{l}\text { Người cùng hoàn } \\
\text { cảnh ốm đau, bệnh } \\
\text { tật }\end{array}$ & 0,0 & 4,7 & 78,7 & 15,0 & 1,7 & 100,0 \\
\hline
\end{tabular}

Kết quả khảo sát cũng cho thấy, mối tương quan có ý nghĩa thống kê giữa cơ cấu kinh tế với mức hỗ trợ của tất cả các thành viên mạng lưới: thành viên gia đình $(\mathrm{p}=0,000)$, họ hàng $(\mathrm{p}=0,001)$, hàng xóm $(\mathrm{p}=0,000)$, bạn bè $(\mathrm{p}=0,000)$, đồng nghiệ $(\mathrm{p}=0,000)$, chính quyền 
địa phương, cơ quan, tổ chức ( $\mathrm{p}=0,000)$, nhân viên $\mathrm{y}$ tế $(\mathrm{p}=0,000)$ và người có cùng hoàn cảnh ốm đau, bệnh tật $(\mathrm{p}=0,007)$. Điều này cho thấy mức độ hỗ trợ của các thành viên MLXH bi ảnh hưởng bởi điều kiện kinh tế.

\subsection{Tiếp cận dịch vu y tế của nguời trong độ tuổi lao động}

Trong khám chữa bệnh, MLXH tạo thuận lợi cho quá trình phục hồi sức khỏe. Khi loại hỗ trợ và phạm vi nguồn hỗ trợ là những yếu tố ảnh hưởng đến hiệu quả của quá trình đó, thì tiếp cận dịch vụ y tế được coi là yếu tố không chỉ quyết định sự phục hồi sức khỏe mà còn quyết định công bằng xã hội trong khám chữa bệnh.
Thực trạng sử dụng dịch vụ y tế của người TĐTLĐ qua sự hố trợ của MLXH được tìm hiểu qua các chỉ số nơi khám chữa bệnh, số lần khám chữa bệnh và chất lượng dịch vụ y tế theo đánh giá của người TĐTLĐ.

\section{- Nơi khám chũa bệnh:}

Khi được hỏi về nơi khám chữa bệnh, người trả lời khảo sát cho biết thường lựa chọn nhiều hơn một địa điểm. Đa số đối tượng khảo sát thường đi khám chữa bệnh ở bệnh viện công lập và chủ yếu ở bệnh viện tuyến huyện và trạm y tế (bảng 3). Việc mời bác sĩ đến khám tại nhà, nơi bán thuốc và tự chữa bệnh được người lao động sử dụng rất ít.

Bảng 3. Sử dụng cơ sở y tế trong khám chữa bệnh theo cơ cấu kinh tế

\begin{tabular}{lllll}
\hline \multirow{2}{*}{ Nơi khám chữa bệnh } & \multicolumn{3}{c}{ Cơ cấu kinh tế } & \multirow{2}{*}{ Chung } \\
\cline { 2 - 4 } & Nông nghiệp & Công nghiệp & Dịch vụ & \\
\hline Bệnh viện trung ương & 21,0 & 11,0 & 25,0 & 19,0 \\
Bệnh viện tỉnh & 24,0 & 3,0 & 18,0 & 15,0 \\
Bệnh viện huyện & 50,0 & 35,0 & 52,0 & 45,7 \\
Trạm y tế & 11,0 & 47,0 & 7,0 & 21,7 \\
Cơ sở y tế tư nhân & 1,0 & 21,0 & 2,0 & 8,0 \\
Bác sĩ đến khám tại nhà & 0,0 & 1,0 & 0,0 & 0,3 \\
Nơi bán thuốc & 1,0 & 2,0 & 1,0 & 1,3 \\
Tự điều trị & 0,0 & 1,0 & 0,0 & 0,3 \\
\hline
\end{tabular}

Kết quả khảo sát cho thấy mối tương quan có ý nghĩa thống kê giữa cơ cấu kinh tế với sử dụng cơ sở y tế tuyến huyện (Pearson ChiSquare $=0,031$ ). Trong khi người TĐTLĐ ở cơ cấu kinh tế nông nghiệp và dịch vụ khám chữa bệnh chủ yếu ở tuyến huyện, những người ở cơ cấu công nghiệp lại khám chữa bệnh chủ yếu ở phòng y tế cơ quan tương đương với trạm y tế xã. Điều này có thể giải thích là các cơ quan, đơn vị tổ chức khám chữa bệnh cho người TĐTLĐ tại đơn vị y tế của cơ quan, tổ chức. Trong khi đó, trạm y tế xã chỉ khám chữa bệnh khi người dân tìm đến.

Kết quả khảo sát này cũng cho kết quả tương tự với kết quả nghiên cứu của Nguyễn Khánh Phương và cộng sự, trong số các cơ sở y tế nhà nước cung ứng dịch vụ khám chữa bệnh cho người có bảo hiểm y tế thì trạm y tế xã và bệnh viện huyện đóng vai trò chủ yếu với $55 \%$ tổng số lượt khám chữa bệnh và lên tới $86 \%$ số lượt người khám chữa bệnh tại cơ sở y tế nhà nước.

- Số lần khám chữa bệnh:

Nhìn chung, phần lớn người TĐTLĐ cho biết họ đi khám chữa bệnh từ 2 đến 5 lần trong một năm (66,4\%). 21,3\% người TĐTLĐ khám chữa bệnh một lần trong một năm. Mối tương quan không có ý nghĩa thống kê giữa số lần khám chữa bệnh với cơ cấu kinh tế (Pearson ChiSquare $=0,064)$. Điều này cho thấy, dù người TĐTLĐ ở thành phần cơ cấu kinh tế nào họ đều khá tích cực đi khám chữa bệnh.

Khi nghiên cứu nhu cầu chăm sóc sức khỏe và tình hình sử dụng dịch vụ $\mathrm{y}$ tế của người có thẻ bảo hiểm y tế tại vùng nông thôn, tác giả Nguyễn Khánh Phương và cộng sự cho biết tỷ lệ đi khám chữa bệnh khi ốm nhìn chung ở mức 
khá lạc quan với mức 58,6\% và số lượt đi khám chữa bệnh bình quân đầu người trong năm trên toàn mẫu là 2 lượt và tần suất đi khám chữa bệnh của nhóm bảo hiểm y tế tự nguyện là cao nhất (3,34 lượt/người/năm), sau đó là nhóm có bảo hiểm $\mathrm{y}$ tế người nghèo $(2,63$ lượt/người/năm) và học sinh (1,74 lượt/ người/ năm) [5].

Bảng 4. Số lần khám chữa bệnh của người TĐTLĐ

\begin{tabular}{lllll}
\hline \multirow{2}{*}{ Số lần } & \multicolumn{3}{l}{ Cơ cấu kinh tế } & \multirow{2}{*}{ Chung } \\
\cline { 2 - 4 } & Nông nghiệp & Công nghiệp & Dịch vụ & \\
Một lần & 21,0 & 22,0 & 21,0 & 21,3 \\
Từ 2 đến 5 lần & 59,0 & 68,0 & 72,0 & 66,3 \\
Từ 6 lần trở lên & 20,0 & 10,0 & 7,0 & 12,3 \\
Tổng & 100,0 & 100,0 & 100,0 & 100,0 \\
\hline
\end{tabular}

- Tiêu chí lựa chọn chất lượng dịch vụ y tế:

Theo ý kiến của người TĐTLĐ, họ sử dụng dịch vụ do người khác giới thiệu dựa trên mười tiêu chí xếp từ thấp đến cao như (bảng 5): Cán bộ y tế giỏi; người bệnh được đón tiếp và chỉ dần rõ ràng; chi phí y tế phù hợp với khả năng chi trả; không phải chờ đợi lâu; có người quen; gần nhà, đi lại dễ dàng; thủ tục khám chữa bệnh và thanh toán viện phí nhanh, chính xác; nhân viên y tế cởi mở, lịch sự, tôn trọng người bệnh; trang thiết bị y tế, thuốc men đầy đủ; tiếp cận dễ dàng với chuyên gia y tế.

Bảng 5. Tiêu chí sử dụng dịch vụ y tế của người trong độ tuổi lao động

\begin{tabular}{|c|c|c|c|c|c|}
\hline \multirow[b]{2}{*}{ STT } & \multirow[b]{2}{*}{ Tiêu chí chọn nơi khám, chữa bệnh } & \multicolumn{3}{|c|}{ Cơ cấu kinh tế } & \multirow[b]{2}{*}{ Chung } \\
\hline & & $\begin{array}{l}\text { Nông } \\
\text { nghiệp }\end{array}$ & $\begin{array}{l}\text { Công } \\
\text { nghiệp }\end{array}$ & $\begin{array}{l}\text { Dịch } \\
\text { vụ }\end{array}$ & \\
\hline 1 & Người bệnh được đón tiếp và chỉ dẫn rõ ràng & 23,0 & 97,0 & 91,0 & 70,3 \\
\hline 2 & $\begin{array}{l}\text { Người bệnh được vận chuyển phù hợp với tình trạng } \\
\text { bệnh }\end{array}$ & 11,0 & 26,0 & 18,0 & 18,3 \\
\hline 3 & Bảo đảm các điều kiện cấp cứu người bệnh & 11,0 & 15,0 & 28,0 & 18,0 \\
\hline 4 & $\begin{array}{l}\text { Thủ tục khám chữa bệnh và thanh toán viện phí } \\
\text { nhanh, chính xác }\end{array}$ & 38,0 & 45,0 & 49,0 & 44,0 \\
\hline 5 & Trang thiết bị y tế, thuốc men đầy đủ & 28,0 & 31,0 & 71,0 & 43,3 \\
\hline 6 & Tiếp cận dễ dàng với chuyên gia y tế & 24,0 & 44,0 & 27,0 & 31,7 \\
\hline 7 & Nhân viên y tế cởi mở, lịch sự, tôn trọng người bệnh & 9,0 & 62,0 & 60,0 & 43,7 \\
\hline 8 & Cán bộ y tế giỏi & 53,0 & 84,0 & 88,0 & 75,0 \\
\hline 9 & Cơ sở vật chất phục vụ người bệnh đầy đủ, sạch sẽ & 7,0 & 25,0 & 53,0 & 28,3 \\
\hline 10 & $\begin{array}{l}\text { Được cung cấp thông tin và tham gia vào quá trình } \\
\text { điều trị }\end{array}$ & 14,0 & 29,0 & 26,0 & 23,0 \\
\hline 11 & Quyền riêng tư được tôn trọng & 7,0 & 17,0 & 30,0 & 18,0 \\
\hline 12 & Đặt được lịch khám chữa bệnh & 12,0 & 19,0 & 27,0 & 19,3 \\
\hline 13 & Chi phí y tế phù hợp với khả năng chi trả & 44,0 & 86,0 & 74,0 & 68,0 \\
\hline 14 & $\begin{array}{l}\text { Ý kiến của người bệnh được tiếp nhận, phản hồi và } \\
\text { giải quyết }\end{array}$ & 3,0 & 6,0 & 16,0 & 8,3 \\
\hline 15 & Không phải chờ đợi lâu & 50,0 & 59,0 & 71,0 & 60,0 \\
\hline 16 & Gần nhà, đi lại dễ dàng & 45,0 & 65,0 & 28,0 & 46,0 \\
\hline 17 & Có người quen & 60,0 & 48,0 & 42,0 & 50,0 \\
\hline
\end{tabular}


Người TĐTLĐ được khảo sát ít lựa chọn những tiêu chí về sự tham gia vào quá trình điều trị và bảo vệ quyền riêng tư. Người TĐTLĐ lựa chọn các tiêu chí đáp ứng nhu cầu trước mắt và chưa đề cao quyền lợi của họ khi đi khám chữa bệnh. Đó có thể là nguyên nhân làm cho việc đi khám chữa bệnh của họ còn thụ động và chưa thỏa mãn mong đợi cá nhân. Họ đặt nhiều mong đợi vào lực lượng y tế.

Kết quả khảo sát cho thấy mối tương quan có ý nghĩa thống kê giữa cơ cấu kinh tế với việc lựa chọn chất lượng dịch vụ y tế của người TĐTLĐ về các tiêu chí: cán bộ y tế giỏi ( $\mathrm{p}=0,000)$; người bệnh được đón tiếp và chỉ dẫn rõ ràng $(\mathrm{p}=0,000)$; chi phí y tế phù hợp với khả năng chi trả $(\mathrm{p}=0,000)$; không phải chờ đợi lâu $(\mathrm{p}=0,000)$; có người quen $(\mathrm{p}=0,035)$; gần nhà, đi lại dễ dàng $(\mathrm{p}=0,000)$; trang thiết bị y tế, thuốc men đầy đủ $(\mathrm{p}=0,000)$; tiếp cận dễ dàng với chuyên gia $\mathrm{y}$ tế $(\mathrm{p}=0,005)$. Nhưng mối tương quan không có ý nghĩa thống kê giữa cơ cấu kinh tế với việc lựa chọn thủ tục khám chữa bệnh và thanh toán viện phí nhanh, chính xác (Pearson Chi-Square $>0,05)$. Điều này có thể do người trả lời khảo sát cho rằng thủ tục khám chữa bệnh và thanh toán viện phí đã được ấn định, khó có thể tác động để thay đổi.

- Chất lượng dịch vụ y tế:

Đánh giá của người TĐTLĐ đối với dịch vụ $\mathrm{y}$ tế mà họ sử dụng (bảng 6) cho thấy dịch vụ y tế thường được cho là tốt và khá ( $46 \%$ và $37,7 \%)$. Điều này chứng tỏ MLXH đã giúp người TĐTLĐ tiếp cận được dịch vụ y tế phù hợp và người TĐTLĐ có niềm tin với nhân viên y tế và cơ sở cung cấp dịch vụ y tế.

Bảng 6. Chất lượng dịch vụ y tế

\begin{tabular}{|c|c|c|c|c|}
\hline \multirow[b]{2}{*}{$\begin{array}{l}\text { Chất lượng dịch vụ } \\
\text { y tế }\end{array}$} & \multicolumn{4}{|c|}{ Cơ cấu kinh tế } \\
\hline & $\begin{array}{l}\text { Nông } \\
\text { nghiệp }\end{array}$ & $\begin{array}{l}\text { Công } \\
\text { nghiệp }\end{array}$ & Dịch vụ & Chung \\
\hline Rất tốt & 5,0 & 2,0 & 4,0 & 3,7 \\
\hline Tốt & 31,0 & 41,0 & 66,0 & 46,0 \\
\hline Khá & 56,0 & 40,0 & 17,0 & 37,7 \\
\hline Trung bình & 8,0 & 16,0 & 13,0 & 12,3 \\
\hline Kém & 0,0 & 1,0 & 0,0 & 0,3 \\
\hline Tổng & 100,0 & 100,0 & 100,0 & 100,0 \\
\hline
\end{tabular}

Có mối tương quan giữa cơ cấu kinh tế với sự đánh giá chất lượng dịch vụ y tế (Pearson Chi-Square $=0,000)$. Đa số người lao động trong khu vực dịch vụ đánh giá chất lượng dịch vụ y tế ở mức độ tốt và hơn $1 / 2$ số người lao động trong khu vực nông nghiệp chỉ đánh giá ở mức khá. Người lao động trong khu vực công nghiệp, cân bằng giữa hai mức đánh giá. Có thể lý giải thực trạng trên là do y tế là một lọai dịch vụ và người lao động trong khu vực dịch vụ chia sẻ nhiều hơn với quan điểm chất lượng dịch vụ y tế nên đánh giá cao hơn so với người lao động trong khu vực kinh tế kia. Mặc dù còn có hạn chế về trình độ chuyên môn, cơ sở vật chất, trang thiết bị kỹ thuật, nhưng các cơ sở y tế công lập tại địa bàn khảo sát đã đạt chuẩn quốc gia về y tế, đặc biệt các trạm y tế xã đều có một bác sĩ.

\section{Kết luận}

Bài viết tập trung phân tích chức năng của MLXH trong việc hỗ trợ xã hội và giúp người TĐTLĐ tiếp cận dịch vụ y tế. Có thể thấy rằng, MLXH trong khám chữa bệnh của người TĐTLĐ ở nông thôn (trường hơp khảo sát) có tính đa dạng. Mạng lưới hỗ trợ này đáp ứng cơ bản nhu cầu khám chữa bệnh của người trong độ tuổi lao động. Sự hỗ trợ của các thành viên trong MLXH có tính đa chiều nhưng chưa sâu và theo chức năng, kinh nghiệm, hiểu biết và nguồn lực có thể huy động được. Ý kiến của 
người TĐTLĐ cho thấy vai trò của chính quyền, tổ chức, đơn vị sử dụng lao động, cơ sở y tế, cũng như các tổ chức chính trị - xã hội còn mờ nhạt, chưa đáp ứng mong đợi của họ về việc cung cấp thông tin về y tế nói chung; thông tin về tổ chức, quản lý và cung cấp dịch vụ chăm sóc sức khỏe, kết nối nguồn lực và với các co sở y tế để tổ chức khám chữa bệnh cho người TĐTLĐ nói riêng.

Kết quả nghiên cứu chỉ giới hạn trong phạm vi đối tượng được điều tra. Cần có những nghiên cứu tiếp theo để xác định những yếu tố ảnh hưởng đến sự hỗ trợ của mạng lưới trong khám chữa bệnh đối với người TĐTLĐ ở nông thôn.

\section{Tài liệu tham khảo}

[1] Faber, A.D., \& Wasserman, S. (2002), "Social support and social networks: synthesis and review", in: J.A. Levy, \& B.A. Pescosolido, (Eds.), Social Networks and Health, Vol.8, tr. 2972, Boston: Elsevier Science Ltd.

[2] Cobb, S. (1976), "Social support as a moderator of life stress", Psychosomatic Medicine, Volume 38, tr. 300-314.

[3] Heaney, C. A., Israel, B. A. (2001), "Social networks and social support", In: Glanz, K., Rimer, B. K., \& Lewis, F. M. (editors), Health Behavior and Health Education: Theory, research, and practice, San Francisco: Jossey-Bass. tr.185-209.

[4] Granovetter, M.S. (1973), "The strength of weak ties", American Journal of Sociology, Vol. 78, tr. 1360-1380.

[5] Nguyễn Khánh Phương và cộng sự (2009), "Nhu cầu chăm sóc sức khỏe và tình hình sử dụng dịch vụ $\mathrm{y}$ tế của người có bảo hiểm y tế tại vùng nông thôn", Tạp chí Y học thực hành (662), Số 5, tr. 61-63.

\title{
Support of Healthcare Social Networks for Rural Working-Age Population
}

\author{
Pham Gia Cuong \\ Department of Social Affairs, Central Commission for Propaganda and Education, \\ 2 B Hoang Van Thu, Ba Dinh, Hanoi, Vietnam
}

\begin{abstract}
The paper analyzes the support of the social networks and access to health services through these networks for rural working-age population from different socio-economic structures, and thereby, identifies the role of social workers in the provision of healthcare support for the named population.
\end{abstract}

Keywords: Healthcare, social support, social network, working-age population 